\title{
Juventudes partidárias e mobilização cívica on-line: 0 caso das eleições presidenciais em Portugal (2011)
}

Flávia Santos

Doutoranda em Ciências da Comunicação e Sociologia (Universidade Nova de Lisboa)

flavsantos@gmail.com

\begin{abstract}
Resumo A internet tem-se revelado para os mais jovens um espaço propício à mobilização e à socialização, permitindo integrar uma coletividade de pessoas jovens com propostas de articulações em comum. Para muitos jovens portugueses conectados de alguma maneira à política, via partidos ou associações, os laços estruturados em redes sociais de amigos (e amigos de amigos) alargam-se cada vez mais e são mediados no âmbito das redes sociais on-line como o Facebook. Este trabalho é resultado de um inquérito on-line aplicado a propósito das eleições presidenciais de 2011 em Portugal. Foram inquiridos jovens inscritos em associações partidárias (JSD e JP) e não partidária (MLS) com o objetivo de verificar os impactos que as mídias digitais, principalmente a internet, podem exercer na vida cívica dos jovens, de que maneira estes recursos são explorados e, efetivamente, se estes meios colaboram no incentivo à participação juvenil nas questões de relevância pública.
\end{abstract}

Palavras-chave: jovens e política, redes sociais, cultura cívica on-line, juventudes partidárias, mobilização cívica.

\section{Introdução}

$\mathrm{E}$ M SE TRATANDo Do PÚblico Jovem, da política e das novas tecnologias, estes três campos estão de fato cada vez mais difundidos. É importante considerar que a população jovem (15-20) e a jovem adulta (23-30) estão cada vez mais inclinadas às novas tecnologias, respondendo com mais facilidade à inovação comunicativa em rede. Esses indivíduos são também mais propensos a aproveitar as novas tecnologias, principalmente a internet, em contextos políticos e de engajamento cívico, o que poderá facilitar ou estimular o envolvimento juvenil nesse campo mediado por novas redes.

A motivação e a participação política dos jovens, consideradas em si mesmas, passam pelo reconhecimento como atores sociais, mediante o amadurecimento do processo de individualização, que nasce a partir da criação pessoal de significado atribuído à política e à socialização nesse mesmo processo. A socialização política dos jovens está estruturada em três tipos de conexões sociais: a rede primária da família, a secundária, ligada às associações, e a terciária, representada pelas redes de amigos. Na intersecção das redes sociais, Calenda e Meijer (2011) são pontuais nesse assunto, ao afirmarem que as mudanças sociais e econômicas, em face da globalização, das novas tecnologias e das mídias, estão fragmentando a forma como os jovens interpretam a polí- 
tica. As redes sociais e os espaços frequentados pelos jovens são cada vez mais determinantes na discussão de vários temas, incluindo-se a política. Este trabalho explora empiricamente o envolvimento político dos jovens portugueses membros de duas juventudes partidárias (JSD/JP) e um grupo não partidário (MLS), a propósito das eleições presidenciais 2011. Aplicamos um inquérito on-line através da rede social Facebook, cujo objetivo foi mapear as práticas e o uso deste meio no envolvimento político, e de que maneira esses recursos são aproveitados. A nossa principal hipótese chama atenção para a maior relevância dos grupos de amigos na vida dos jovens em detrimento da família com o advento e o uso intenso da internet, sendo este local um espaço de socialização para assuntos ligados à política e ao mesmo tempo às novas relações de sociabilidades.

\section{Jovens e Cultura Cívica on-line}

A relação mais frequente entre os jovens e as TICs sugere pensar na absorção de novos valores e culturas de consumo. A internet tem sido um dos meios por excelência na afirmação de vários projetos com características reflexivas e autônomas, principalmente também no âmbito político, mediante a relação entre mobilização, participação sociopolítica e uso da internet como instrumento dessa mesma mobilização. A participação política não é uma variável independente e muito menos se esgota com o exercício do voto. É em si revelada em vários níveis envolvendo interesse político, informação, socialização, integração e mobilização (Cruz, 1989).

O uso da internet na promoção de manifestações políticas baseia-se principalmente em práticas descentralizadas, através da construção de um espaço cooperativo que oferece informações vindas das mais variadas fontes e que podem enriquecer as práticas coletivas. A imediaticidade e a interatividade das ferramentas deste meio tornam-nas particularmente úteis no processo de mobilização para ações políticas e sociais. As tecnologias de informação e comunicação favorecem a ação política nos casos em que os indivíduos já têm interesse pelas causas em questão (Abílio, 2006, p. 208).

A definição de tecnologia que está por trás da internet compreende a soma de um dispositivo, ${ }^{1}$ das das suas aplicações, os contextos sociais de uso e os arranjos sociais e organizacionais que se constituem à sua volta. Assim, a compreensão da relação que se estabelece entre um ou vários sujeitos e o discurso produzido através da internet são uma parte essencial da compreensão da própria natureza destas tecnologias, na medida em que permite explicar os seus próprios processos de constituição.

A dimensão sociopolítica e o uso da internet mostram que as práticas da ação política encontram, neste meio, dispositivos que servem tanto para mobilizar e socializar quanto para integrar uma coletividade de sujeitos com propostas de articulações em comum. Como afirma Gustavo Cardoso (2006), os índices elevados de mobilização política na internet, por exemplo, estão associados a práticas de levantamento de informação sobre diversas questões, ou seja, reforçam os projetos de autonomia como capacidade para refletir acerca da realidade política e social, propiciando aos agentes as ferramentas de que precisam para tomar suas decisões sem constrangimentos (2006, p. 70).

As novas demandas criativas no contexto on-line no âmbito sociopolítico, bem como a expansão das redes sociais dos jovens "nativos digitais", propõem o aparecimento de um novo paradigma relacional, comunicativo e interventivo desenvolvido em rede. $\mathrm{O}$ termo "Civic Life On-line" é largamente utilizado por autores americanos (Bennett e Xenos 2008; Montgomery, 2008) para explicar a produção, o consumo, a comunicação e a interação explorados pelos mais jovens no ambiente on-line. A vida cívica desencadeada na internet não apenas reforça o fortalecimento dos laços conectivos baseados em rede de amigos, mas também o reconhecimento de que os mais jovens podem ser atores sociais independentes, criando suas próprias narrativas políticas, suas escolhas, e projetando suas identidades num espaço coletivo (Bennett, 2008, p. 3). A possibilidade de criar processos comunicativosinterativos e comutáveis na internet é em si um ato político, como bem sublinha Mark Poster (2000). O movimento da troca é desterritorializado, mas, ao mesmo tempo, (re)territorializa as mesmas trocas, formando um novo tipo de relação política, partilhado na rede. Destas trocas, surgem novas redes políticas planetárias, emergindo o que Poster chama de a figura do "netcidadão" (Poster, 2000, p. 30).

Sobre as práticas participativas e de mobilização on-line, as páginas de blogs e microblogs Twitter, que permitem a criação de conteúdos e partilha de conhecimento, os vídeos projetados no canal YouTube, e mais expressivamente os sites de redes sociais, Facebook, hi5 etc. são os canais mais explorados como 
recursos comunicativos, permitindo reconfigurar os diversos tipos de participação política off-line, desde a partidária, associativa, bem como a caracterização de novas formas de mobilização, tais como os protestos, as assinaturas de petições on-line e os Flash Mobs. $^{2}$

Neste trabalho, uma maior atenção é dada aos sites de redes sociais, especialmente o Facebook, pelo fato de este conter maior número de aplicativos extras e de usuários em Portugal e no mundo. Os sites de redes sociais buscam conectar pessoas, proporcionando sua comunicação. Funcionam orientados pelo princípio da interacção social e podem ser utilizados para constituir laços sociais na rede e fora dela. Os indivíduos, através de páginas de perfis, mantêm conexões diretas (amigos) e indiretas (amigos de amigos). A conexão também pode ser feita através de comunidades de temáticas variadas, nas quais existem ferramentas de discussões, como sistemas de fóruns para comunidades, envio de mensagens para cada perfil, envio de mensagens para comunidades, amigos e para amigos de amigos.

Além de proporcionar a interação entre pessoas conectadas, as redes sociais na internet buscam a socialização on-line com pessoas que dividem o mesmo território de práticas e interesses. Em termos de interatividade, o Facebook oferece várias propostas de conectividade. Esta rede social agrega diversos aplicativos que a transformam não apenas em um espaço de proximidade com outras pessoas, mas também em um espaço interativo ampliado, o que faz com que os usuários mantenham-se por mais tempo dentro desta rede, inclusive executando outras funções, tais como os chats de conversação, jogos, fóruns e questionários, sem perder a conectividade social com outros que compartilham a mesma rede. O desenvolvimento de jogos é um exemplo que ilustra a extensão da conectividade do Facebook. Nesta rede, os jogos são também chamados de "sociais", pois resultam de um valor construído dentro da rede social. Assim, vários jogos $^{3}$ do Facebook precisam que os jogadores cooperem com seus amigos para vencer outros grupos. Por exemplo, o jogo FarmVille mostra que a diversão está em competir diretamente com seus amigos.

Assim, as redes sociais on-line refletem e complexificam a interação de grupos off-line (Recuero, 2006). As comunidades ou grupos, no interior destas redes, são criados para um espaço de discussão, e o sentido de comunidade pressupõe relações entre os seus membros: a interatividade. No caso das comu- nidades on-line, Recuero afirma que a interatividade não é uma característica do meio, mas a extensão em que as mensagens, numa dada sequência, se relacionam umas com as outras, especialmente na extensão em que mensagens posteriores têm relação com as anteriores.

O sentimento de pertença é outro elemento importante da comunidade on-line. Ele é explicado por Palacios (1998) como um sentido de ligação. A comunidade é constituída também a partir de sentimentos, pois: "Os participantes reconhecem-se como parte de um grupo e responsáveis pela manutenção das relações." (Palacios, 1998, p. 73). O sentimento de pertença é visto como uma das condições necessárias para a existência de comunidades nos sites de rede sociais, pois para que uma comunidade possa ser caracterizada, necessita, antes de tudo, de um sentimento de pertença, ou seja, de se ter algo em comum. O sentimento de pertença pode também ser um projeto de construção na rede internet. Em nosso caso, acreditamos só fazer sentido falar em comunidades on-line quando existe também uma pertença off-line, como é o caso das associações juvenis partidárias e não partidárias da nossa amostra.

\section{Explorar o cibercampo: estratégia metodológica e caracterização da amostra}

Ao longo de toda a discussão feita até agora, consideramos ser a internet o espaço para novas formas de ação política. No entanto, mais do que afirmar, é preciso definir os territórios de ação para assim compreender quais são de fato essas práticas, identificar os sujeitos e perceber de que maneira estes dão sentido às suas ações na rede rede e fora dela, motivados por questões sociopolíticas, constituindo-se isto nosso objeto de interesse.

Tendo como perspectiva a hipótese principal deste estudo, sobre a interferência das novas tecnologias no modo de participação política dos jovens, este trabalho preocupou-se empiricamente em perceber o envolvimento político deles a partir do uso que fazem da internet. Para tanto, foram testadas as hipóteses apresentadas no início deste trabalho, verificando de fato a pertinência da cultura cívica on-line no contexto português, constatando as experiências on-line

2. São aglomerações instantâneas de pessoas em um local público para realizar determinada ação inusitada previamente combinada, as quais se dispersam tão rapidamente quanto se reúnem. Este tipo de mobilização está cada vez mais sendo utilizado em manifestações políticas.Ver: Heany, Francis. "The Short Life Short Life of Flash Mobs", StayFree! Magazin. Disponível em: http://www.stayfreemagazine.org/archives/24/ flash-mobs-history.html.

3. Alguns exemplos: Yakuza Lords, Mafia Wars. 
diferenciadas dos modos tradicionais de participação política, identificando os locais das práticas e o aproveitamento, pelos jovens, dos recursos disponíveis na internet. $\mathrm{O}$ contexto das eleições presidenciais de 2011, em Portugal, foi bastante propício à aplicação dos questionários e à verificação deste fenômeno em contextos específicos.

Recorremos também ao método da etnografia virtual ou Netnografia. Este método parece atender algumas das exigências iniciais da investigação no cibercampo, considerando os grupos juvenis representados no Facebook.

A etnografia virtual, como tipo de pesquisa de abordagem qualitativa, tem sido considerada em vários estudos. Christine Hine (2000), em sua obra Virtual Ethnograpy, avalia a internet como espaço de práticas culturais, sendo este meio o artefato para desenvolver novas produções de sentido. Para Hine (2000), a etnografia virtual pode ser usada para desenvolver a percepção do sentido da tecnologia e dos espaços socioculturais que são por ela estudados. Por isso, a etnografia virtual tem espaço assegurado nas pesquisas em que os objetivos incluem saber a real utilização da tecnologia pelas pessoas.

Baseada nos passos da etnografia tradicional, cuja aplicação metodológica sempre esteve relacionada a ir para algum lugar, no sentido literal da expressão, com o intuito de observar e interagir com determinada comunidade, com tribos, inserindo-se o investigador dentro da realidade observada, a etnografia virtual modifica a relação espaço-temporal e apresenta-se num contexto de mediações cujas práticas dos indivíduos observados estão alojadas no ambiente on-line.

Jones (1997) fala de ciberarqueologia das comunidades on-line como forma de investigar estas comunidades mediadas pelo computador. $\mathrm{O}$ autor explica que, da mesma forma como o arqueólogo considera os artefatos de uma cultura, é possível estudar as comunidades virtuais a partir dos artefatos culturais que elas produzem e estabelecem uma pesquisa de longo prazo. Para o autor, focar nos artefatos culturais de comunidades on-line significa manter a atenção em como eles estruturam a dinâmica comunal na rede.

A partir desta prática metodológica e considerando as nossas hipóteses de trabalho, optamos por observar o universo das redes sociais on-line de grupos de jovens ligados a associações partidárias e não partidárias presentes no Facebook. A escolha partiu do critério off-line. Selecionamos as entidades juvenis partidárias mais atuantes em nível nacional e outras sem vínculo a partidos políticos, mas direcionadas para a temática sociopolítica e à cidadania. Foram convidadas a participar do nosso inquérito, cinco entidades, mas apenas três ${ }^{4}$ delas atenderam à nossa solicitação, a saber: Juventude Social Democrata (JSD), Juventude Popular (JP), ambas ligadas a seus respectivos partidos, e Movimento Liberal Social (MLS), não partidária. As questões contidas no inquérito eram comuns a todos e foram enviadas a partir da plataforma websurvey, através de um link em que os participantes poderiam responder às questões on-line. Optamos pelo envio do link através do Facebook e pedimos aos responsáveis pelas comunidades da amostra que o reenviassem aos membros.

A estratégia do websurvey permitiu-nos verificar quantitativamente a percentagem real do número de membros presentes no Facebook e o número de inscritos na lista oficial das respectivas instituições. Esta verificação nos foi útil para perceber em termos qualitativos o grau de participação individual e a caracterização do perfil dos membros on-line. Neste inquérito, optamos por não direcionar os dados à caracterização ideológica das associações participantes, concentrando-nos somente nos impactos que as mídias digitais, especialmente a internet, podem exercer na vida cívica dos jovens, de que maneira estes recursos são explorados e, efetivamente, se estes meios colaboram no incentivo à participação juvenil nas questões de relevância pública.

Quanto ao percurso metodológico, é importante considerar que a internet, como campo de ação estratégico, é bastante recente e por isso implica alguns níveis de dificuldades. A aplicação do websurvey limita em alguns aspectos o recolhimento de dados sobre a população inquirida, pois elementos como a falta de contato pessoal entre o investigador e os inquiridos, o fator surpresa, a falta de confiança no trabalho do investigador e a forma como as instituições divulgam e distribuem os questionários contribuem para um declínio no número de respostas. Na tentativa de ultrapassar alguma dessas barreiras, Kozinets (2010) sugere que o investigador seja o mais participativo possível nas comunidades que pretende estudar, cultivando estratégias de confiança entre os inquiridos. $\mathrm{O}$ autor sugere, por exemplo, a criação de um $b \log ^{5}$ no qual o investigador possa relatar a sua experiência de modo a ultrapassar a barreira do desconhecido.

A coleta dos dados decorreu entre dezembro de 2010 até 23 de janeiro de 2011, abrangendo o período pré-eleitoral das presidenciais. Contabilizamos um número total de 246 respostas. Se compararmos o número de respostas obtidas com o número de membros inscritos on-line nas respectivas entidades, verificamos que este é relativamente baixo, conforme se pode comprovar no Quadro 1. 
Quadro 1 - Facebook: Número de inscritos de membros nos grupos até 27 de Janeiro de 2011

\begin{tabular}{|c|c|c|}
\hline JSD & JP & MLS \\
\hline 11.178 & 1.096 & 481 \\
\hline
\end{tabular}

Uma das explicações para a não adesão de alguns participantes à websurvey, além das limitações metodológicas já mencionadas, poderá residir no problema da continuidade e descontinuidade participativa entre os membros. Kozinets (2010) alerta para o fato de que, durante o processo metodológico on-line, ao considerarmos o universo de uma determinada comunidade, é preciso avaliar os indivíduos consoante a interatividade e o tempo de permanência no grupo. Um membro que apenas visita uma determinada comunidade, mesmo que seja para ler um post no fórum, em um espaço de tempo irregular, não pode ser considerado um membro ativo, pois sua participação é "passiva" e limitada à observação.

\section{Quem está on-line?}

Embora os jovens pertencentes às associações participantes estejam distribuídos em todo o país, a maior parte dos inquiridos concentra-se no eixo Lisboa-Setúbal (73\%) e, em menor percentagem, distribuídas em algumas regiões do norte do país: Viseu (8\%), Esposende (6,8\%), Porto - Vila Nova de Gaia (12\%). Numa primeira fase do inquérito, foi solicitado aos inquiridos que preenchessem os campos relacionados à sociografia, de modo a identificar o gênero, a faixa etária, a escolaridade e a inserção no mercado de trabalho.

Quadro 2 - Gênero

\begin{tabular}{|l|c|c|}
\hline & $\mathbf{N}$ & $\%$ \\
\hline Masculino & 178 & $72,3 \%$ \\
\hline Feminino & 68 & $27,6 \%$ \\
\hline TOTAL & 246 & $100 \%$ \\
\hline
\end{tabular}

Quadro 3 - Faixa Etária

\begin{tabular}{|c|c|c|}
\hline & N & $\%$ \\
\hline $15-20$ & 42 & $16,7 \%$ \\
\hline $23-30$ & 202 & $82,3 \%$ \\
\hline
\end{tabular}

No que diz respeito ao sexo dos inquiridos, a proporção de membros do gênero masculino participantes e presentes nas comunidades on-line foi maior $(72,3 \%)$ do que a do gênero feminino, que contabilizou uma percentagem de 27,6\%. A maior presença dos jovens do sexo masculino tende a confirmar este perfil de usuário de computador, apurado em outros inquéritos (Cardoso, Cheta e Espanha, 2008), sendo o mais recente divulgado pela Obercom, em julho de 2010, sobre os Nativos Digitais, perfil este ao qual fizemos referência no início do texto.

A faixa etária tem-se revelado um interessante indicador do universo juvenil quanto ao uso específico que este faz do computador e da internet. Os dados do último relatório Obercom revelaram que há assimetrias nas atividades desenvolvidas on-line e que estas merecem ser observadas. Os grupos etários de 10 aos 15 anos preferencialmente utilizam a internet para jogos, download de jogos e de software, busca de informações para fins educacionais e para a comunicação por chat. A procura por pesquisas generalistas on-line, e-mails, e pela leitura e criação de blogs são destacadamente atividades de uma população adulta, conforme dados do Estudo Obercom (2010, p. 4-33). ${ }^{6}$

Uma outra etapa deste estudo foi o levantamento do grau de escolaridade dos inquiridos. Relativamente a isto, constatou-se que a formação acadêmica superior prevaleceu sobre as demais, conforme o Quadro 4 , sendo que $17,7 \%$ responderam ter concluído o ensino secundário, 62,6\% disseram-se licenciados e $19,7 \%$, pós-graduados.

O percurso educacional dos inquiridos, cuja prevalência foi o de nível superior e de pós-graduação, é um indicador importante de algumas associações entre literacia, uso da internet e condição socioeconômica de alguns grupos da sociedade portuguesa. No que diz respeito à inserção no mercado de trabalho, observou-se que, nos grupos partidários, a maior parte dos inquiridos respondeu não estar exercendo nenhuma atividade profissional, enquanto na entidade não partidária verificou-se o contrário, conforme as duas situações demonstradas no Gráfico 1.

Algumas explicações sociológicas para estes resultados podem advir do contexto socioeconômico durante a transição para a vida adulta. Fatores como o prolongamento da vida escolar, de ordem familiar ou econômica, a exemplo das baixas perspectivas em face do mercado de trabalho e da precariedade do emprego, podem explicar o baixo número de jovens licenciados, não exercendo uma atividade profissional. Por outro lado, o perfil das associações também

6. Obercom é o nome de uma entidade voltada para a observação da comunicação, a qual disponibiliza o relatório "Nativos Digitais Portugueses: idade, experiências e utilizações das TICs". Obercom, julho 2010, citado no texto por oferecer dados cujo objetivo é entender até que ponto os jovens portugueses são efetivamente nativos digitais e se há diferenças visíveis entre os usuários de internet, dentre aqueles dos 10 aos 15 e dos 16 aos 74 anos. 
encontra alguma razão para este resultado. Em termos quantitativos, e devido ao fato de o maior número de respostas recolhidas ser oriundo das juventudes partidárias, nestas instituições, o número de jovens entre os 18 e 25 anos é relativamente maior. Diferentemente, na MLS prevalece a tendência do grupo ‘jovens adultos' (25-30), já com alguma experiência profissional, amadurecimento escolar e acadêmico.

\section{Gráfico 1}

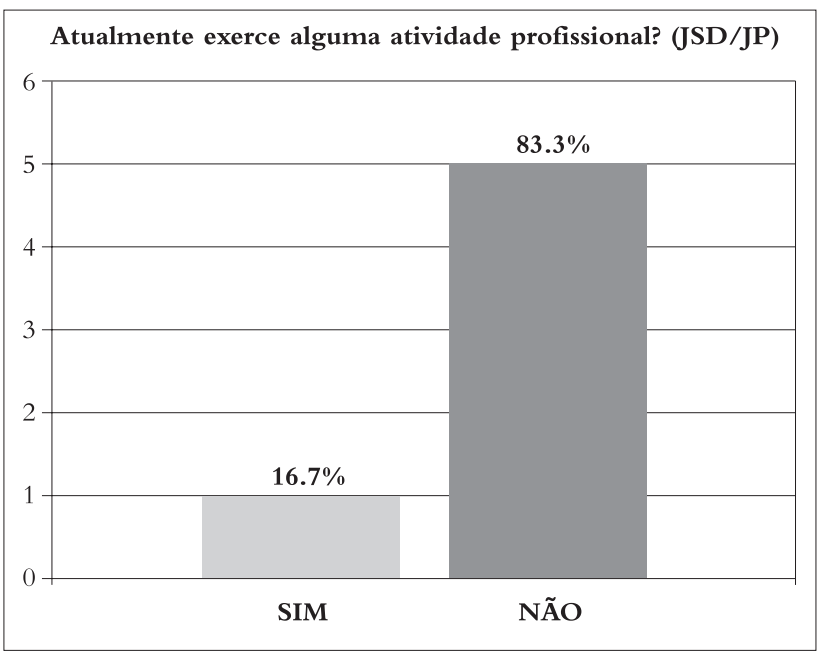

\section{Cultura cívica on-line}

Sobre o uso específico da internet, este estudo buscou dados que evidenciassem se os inquiridos utilizam-se deste meio na busca de informações sobre questões políticas. Conforme ilustra o Gráfico 2, $78 \%$ dos inquiridos responderam utilizar a internet imbuídas deste propósito, com muita regularidade, o que implica acessar a internet duas ou mais vezes por dia, enquanto 25\% deles disseram utilizá-la com alguma regularidade, e, neste caso, o acesso à rede cai para pelo menos uma vez por dia. ${ }^{7}$ Apesar de a idade média dos inquiridos estar entre 18 e 30 anos (que, como visto anteriormente, trata-se de um público maduro no uso deste meio), a parcela de jovens adultos (25-30) foi o grupo dos inquiridos que respondeu fazer maior uso da internet e das redes sociais para expressar questões sociopolíticas.

Em seguida, inquirimos sobre os locais mais acessados na internet. As redes sociais sobressaíram-se com mais relevância, em especial o Facebook. ${ }^{8}$ Além desta rede, os inquiridos responderam, numa questão complementar aberta, que também fazem uso de ou- tras redes sociais, tais como Hi5, Twitter e MSN, na ordem de preferência.

Gráfico 2 - Internet e Política

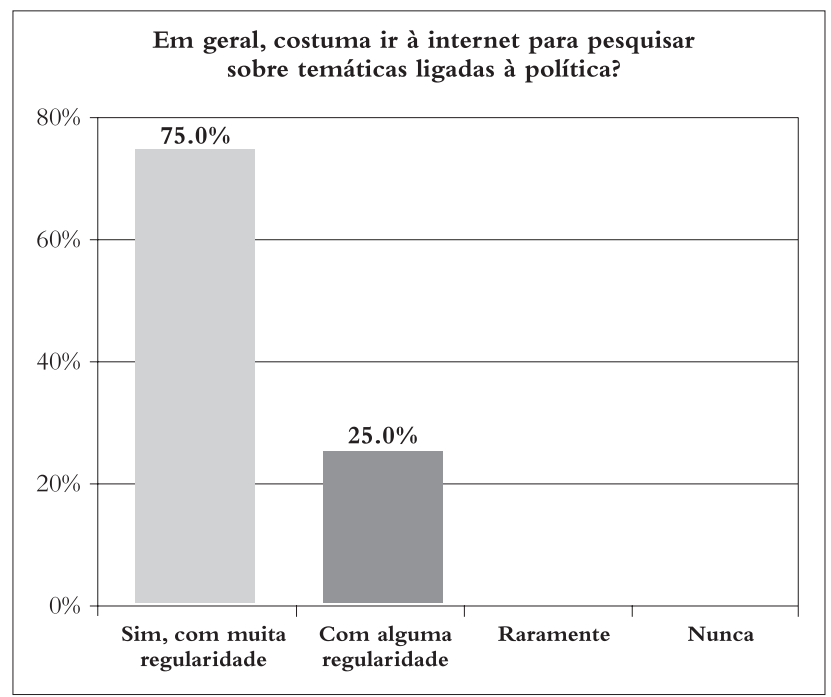

Quanto à frequência de acessos às redes sociais, o Facebook permaneceu no topo dos acessos diários, sendo que $58,7 \%$ responderam acessá-la uma vez por dia, e outros $26 \%$, duas ou mais vezes por dia, segundo ilustra o Gráfico 3. A percentagem daqueles que acessam as redes sociais com menos frequência, ou seja, apenas uma vez por semana, foi de $15 \%$.

Gráfico 3 - Frequência de acesso as redes sociais

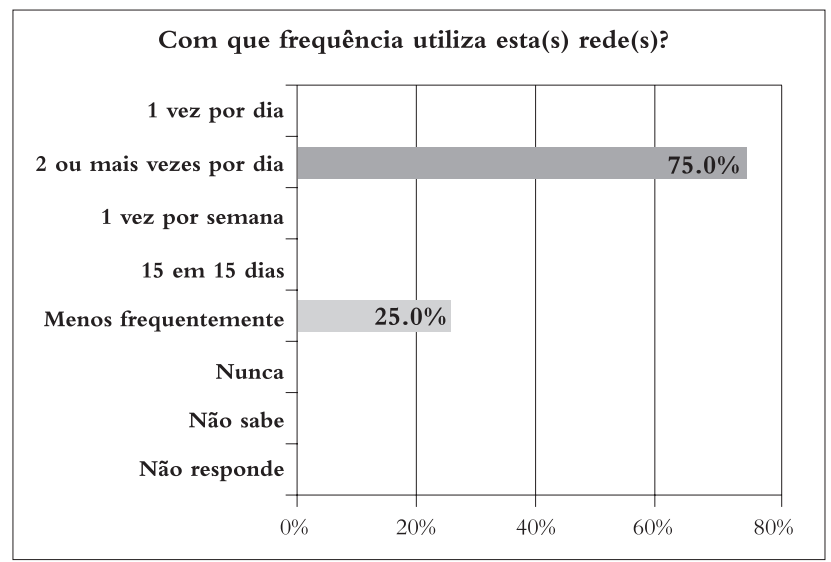

No que diz respeito à permanência, às atividades e ao grau de participação no grupo ao qual pertencem no Facebook, destacamos que $75 \%$ dos jovens inquiridos responderam estar inscritos na comunidade dos respectivos grupos há mais de seis meses. Quanto à frequência, o número de vezes em que os membros visitam as páginas de seus grupos é equivalente ao uso

7. Relativamente aos locais físico de acesso à internet, a maior parte dos inquiridos respondeu acessar a rede a partir de casa (62\%), a seguir na escola, universidade (21\%).

8. Em Portugal, as primeiras redes sociais a ganhar grande popularidade foram o Hi5 e o MySpace. Mas, nos últimos cinco anos, o Facebook tem ganho popularidade e já conta com dois milhões de utilizadores ativos, conforme os números da plataforma Facebaker.com 
que fazem das redes sociais no acesso diário, ou seja, pouco. Quando utilizam o Facebook, conforme Gráfico 4, muitos deles não se esquecem de visitar a comunidade, sobretudo no contexto das eleições de 2011.

Gráfico 4 - Frequência de acesso aos grupo no Facebook

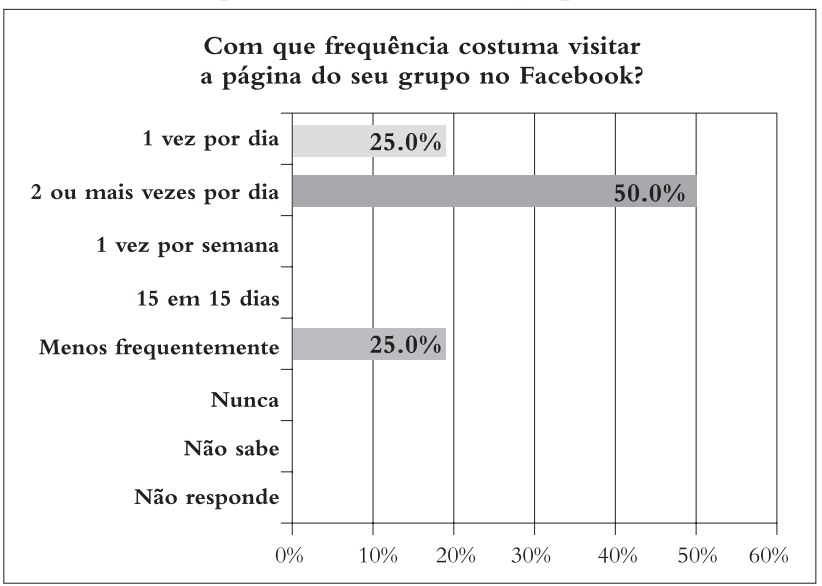

Numa questão aberta, inquirimos sobre o nível de engajamento na rede e fora dela, mediada através da participação off-line dos membros em eventos divulgados na página dos seus respectivos grupos. $\mathrm{Na}$ totalidade, verificamos que mais de $50 \%$ dos jovens disseram participar dos eventos divulgados na comunidade, conforme Gráfico 5. Muito embora seja importante sublinhar que o contexto eleitoral motiva ideologicamente os jovens, sobretudo aqueles conectados aos grupos juvenis partidários, este ponto abre caminhos para posteriores estudos fora do contexto eleitoral, o que, eventualmente, poderá possibilitar a comparação com o nível de engajamento on-line, fora daquele contexto.

Gráfico 5 - Grau de participação

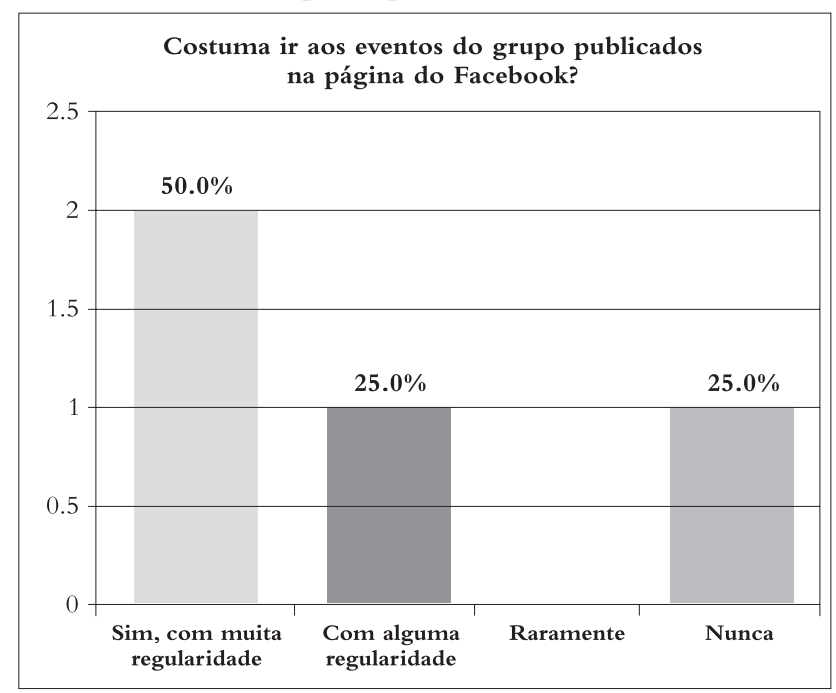

Além das páginas de redes sociais on-line, foi pedido aos inquiridos, numa questão aberta, para citarem outras utilizações que faziam da internet. Ordenamos as preferências citadas conforme o Gráfico 6.
A maior parte dos inquiridos respondeu utilizar a internet para realizar pesquisas as mais variadas: acadêmicas, temas generalistas, dentre outras. Em segundo lugar na ordem de preferência, está a utilização de contas de e-mail e lista de e-mails. O uso da internet para o leitura de notícias e a utilização de blogs aparecem na lista, sendo que a frequência de ambos quase coincide, considerado o número de respostas obtidas.

Gráfico 6 - O consumo da internet pelos jovens

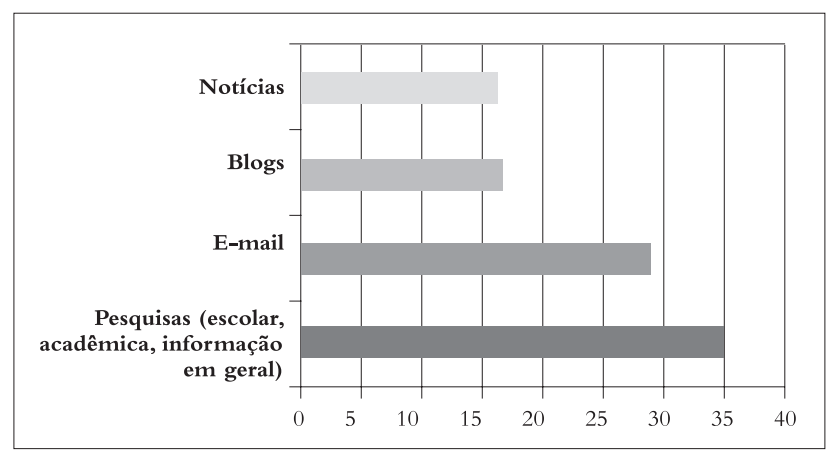

O impacto social dos blogs em Portugal, referenciado em algumas pesquisas (Cardoso, Cheta e Espanha, 2008; Canavilhas, 2006; Carvalho \& Casanova, 2010) mostra que a blogosfera consolidou-se como mais um meio informativo de consumo e reflexão. O nível de consumo das notícias, quase equiparado ao do uso dos blogs, sugere a hipótese sobre o uso deste aplicativo como novo espaço opinativo de intervenção política, baseado no consumo de informação. Sobre o perfil de alguns bloggers portugueses, Carvalho \& Casanova (2010) trazem dados que indicam ser a população consumidora de blogs em Portugal relativamente homogênea, possuidora de recursos socioeducacionais e socioeconômicos elevados, constituída por homens, e que acumula aspectos de uma cidadania ativa, demonstrando participação intensa quer na esfera de debates, quer noutras atividades cívicas (p. 113).

\section{As eleições presidenciais de 2011}

As duas primeiras seções do inquérito permitiram-nos testar as hipóteses teóricas discutidas anteriormente a respeito de uma cultura cívica on-line e a utilização da internet com propósitos sociopolíticos. A terceira e a última parte do inquérito incluiu questões focadas no contexto das presidenciais de 2011. Neste espaço, quisemos mapear o grau de satisfação dos jovens com a democracia política no país, inquiri-los sobre a relevância que dão às redes sociais primária (família) e terciária (amigos) na discussão sobre assuntos políticos, e, por fim, a utilização das plataformas on-line no decorrer do período eleitoral. Sobre a forma como a democracia funciona em Por- 
tugal, tal como demonstrado no Gráfico 7, metade dos inquiridos respondeu não estar totalmente satisfeita com o contexto político do país, mantendo-se assim a estatística global da baixa motivação juvenil com as estruturas democráticas, conforme, a seguir, demonstrado nas transcrições de algumas das respostas dadas ao inquérito:

"Acho que existe muita burocracia para resolver certos problemas e se deixa escapar o essencial que são os problemas das pessoas". (Moça, 22 anos, membro juvenil partidário, Esposende)

"Funciona muito bem para os ricos e muito mal para os pobres”. (Moça, 21 anos, membro juvenil partidário Ponte da Barca)

"Falta de partidos que respondam à minha visão política” (Rapaz, 34, membro não partidário, Lisboa)

Gráfico 7 - Grau de satisfação

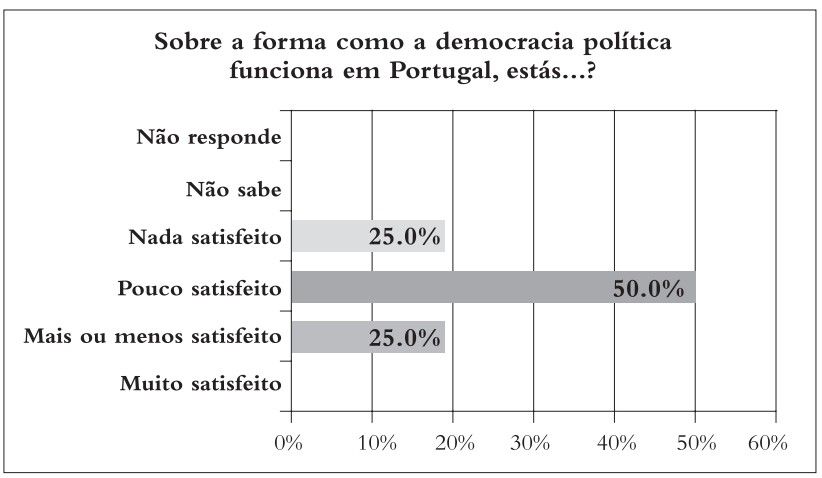

Quando inquiridos sobre a rede social a que mais recorrem ao discutirem assuntos ligados à política, 75\% dos jovens disseram conversar sobre esse tema mais vezes com os amigos do que com a família, conforme Gráfico 8. Estes dados confirmam a hipótese discutida por Calenda \& Meijer, sobre a migração de interesses conectivos cada vez mais centrados nas relações extrafamiliares mediadas pelas novas tecnologias, sendo a internet um desses espaços de conversação.

Assim, o fluxo contínuo de interação mediada por computador ganha espaço no contexto de socialização política alargada, a partir da presença de outros interlocutores e da aquisição de novos conteúdos que poderão exercer grande peso no comportamento e na atitude, direcionando alguns jovens e nativos digitais às novas escolhas, sobretudo políticas.

As questões seguintes do inquérito incidiram sobre o consumo informativo e a utilização da internet no decorrer da campanha eleitoral. Imbuídos deste intuito, questionamos sobre os meios de comunicação mais utilizados pelos jovens durante o período de campanha eleitoral das presidenciais de 2011. Para isso, foram utilizadas as categorias de resposta sempre, quase sempre, às vezes, pouco e raramente. De acordo com o Gráfico 9, com os dados retornados, a internet foi o único meio em que os inquiridos responderam acessá-lo sempre, ou seja, revelando um acesso fiel a este meio. A seguir, a televisão e o jornal foram as mídias utilizadas com grande frequência: $46 \%$ afirmam ver quase sempre televisão e 35\% afirmam o mesmo em relação aos jornais. O rádio foi o meio sobre o qual os inquiridos declararam largamente fazer menor uso: 15\% afirmam utilizar raramente esta fonte de informação. Como fonte não midiática, inserimos as opções 'família' e 'rede de amigos' a fim de obter informação sobre as eleições. Observados os dados retornados, o papel da 'família' permaneceu secundário, pelo qual 66,7\% dos jovens responderam que raramente consultaram seus pais para obter mais informações sobre as eleições, enquanto mais de $50 \%$ responderam que às vezes consultavam os amigos para informações complementares sobre as eleições. Assim, considerando esses dados, é relevante

Gráfico 8 - Redes Sociais e Política

Com que frequência diria que discute política ou assuntos de interesse público com a sua família e amigos?
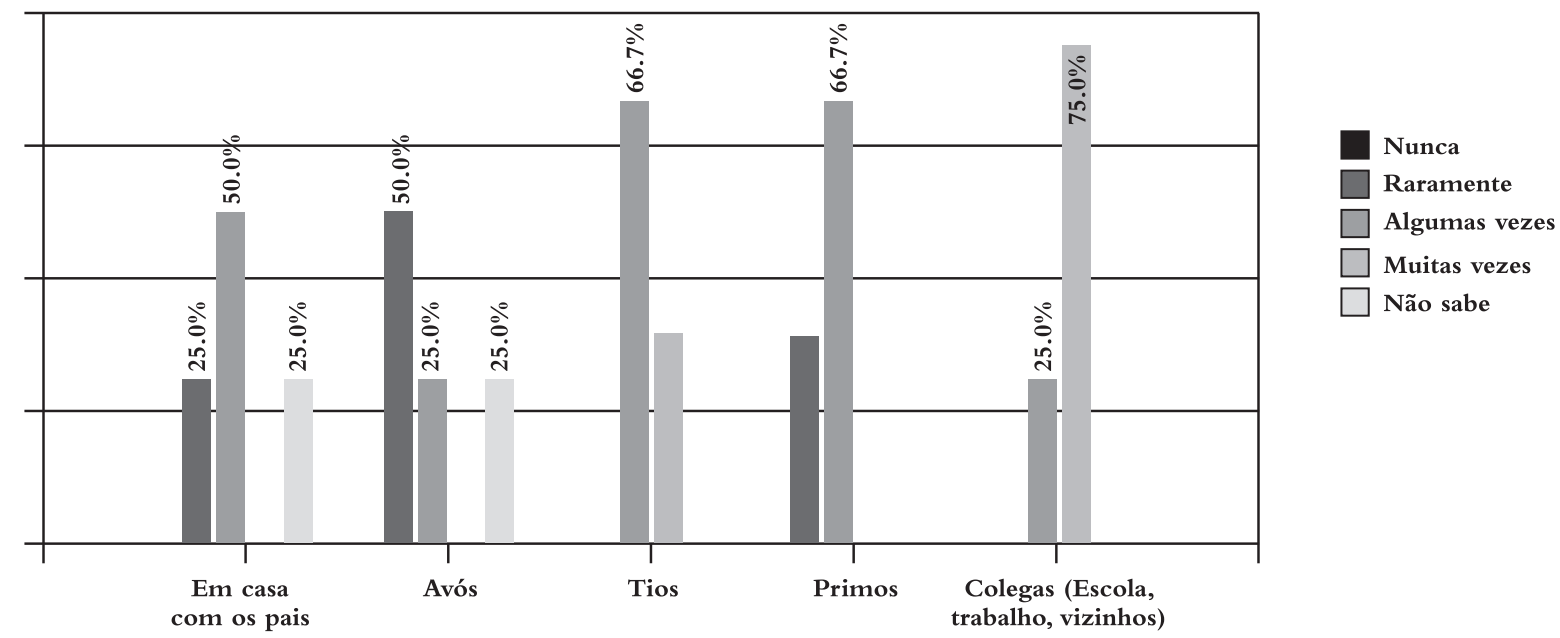
sublinhar os diferentes modos de socialização e individualização política interceptados nas redes sociais e mídias. Quanto a isso, as mídias mostraram ser mais relevantes no consumo de informação e na apropriação de conhecimento do que as redes sociais da família e dos amigos, pois estas são mais frequentes num contexto alargado de socialização política e muitas vezes restritas aos lares.

Gráfico 9 - Presidenciais 2011 e o uso dos media

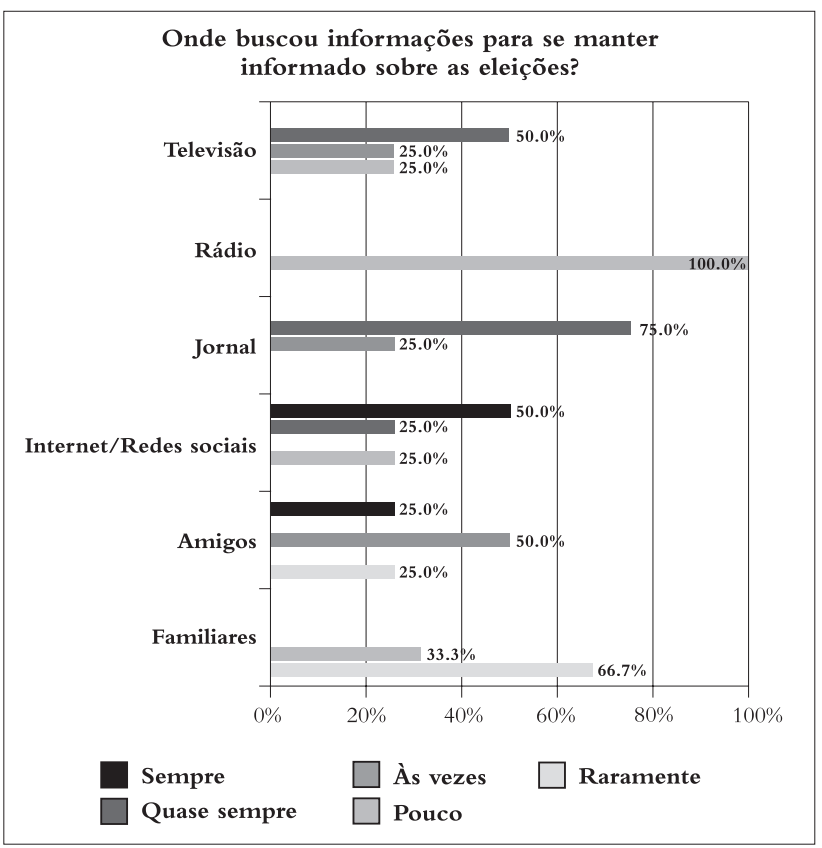

Sobre a conduta participativa dos jovens referente à utilização da internet durante as presidenciais de 2011, inquirimos se estes fizeram uso das redes sociais e da internet, sendo que também foi-lhes solicitado para especificarem o tipo de uso empregado. Do total, 75\% dos jovens responderam sim ao uso sociopolítico da internet, através de blogs e do Facebook, enquanto $25 \%$ responderam não ter feito nenhuma utilização daquelas mídias, conforme Gráfico 10.

Gráfico 10 - Uso sociopolítico da internet

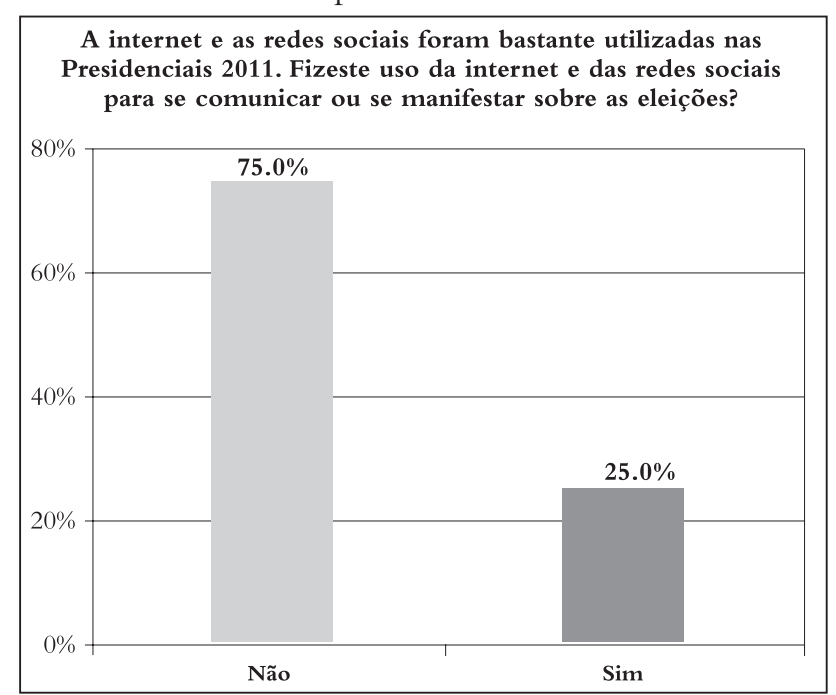

A seguir, numa questão aberta, alguns inquiridos especificaram o tipo de utilização e a participação em eventos on-line:

"Petições, protestos organizados a partir do on-line". (Rapaz, 32 anos membro do MLS).

Consultei as páginas dos candidatos bem como alguns blogues de apoio, para me esclarecer e informar acerca de cada candidato. (Moça, 22 anos, membro JSD)

"Mandei mensagem pelo facebook, mandei e-mails, utilizei blog". (Moça, 21 anos, membro da JSD)

Relativamente à importância dada à internet pelos jovens na mobilização dos interesses políticos, os inquiridos foram convidados a concluír o inquérito, expressando a opinião sobre este tema. Verificamos que os jovens portugueses desta amostra encaram de uma maneira muito positiva a relação entre juventude, política e internet, e se sentem estimulados a utilizar as novas tecnologias, fortalecendo os laços de uma cultura cívica on-line:

"Acho que é uma forma rápida e útil de chegar a todos, e mobilizar mais os jovens”. (Moça, 22 anos, membro da JSD)

"Para os jovens é a forma mais simples de obter a informação. Funde informação tradicional (partilha de notícias) com debate público" (Rapaz, 28 anos membro do MLS)

“'É o meio mais direto de chegar aos jovens e de ouvir a sua opinião e o que os preocupa”. (Rapaz, 29 anos membro da JSD)

\section{Conclusão}

Para muitos jovens portugueses conectados de alguma maneira à política via partidos ou associações, a rede social estruturada na família tem um papel secundário no que diz respeito à partilha de conhecimento sobre política. Os laços estruturados em redes sociais de amigos (e de amigos de amigos) alargam-se cada vez mais e são mediados no âmbito das redes sociais on-line, como o Facebook.

No contexto eleitoral das eleições presidenciais de 2011 em Portugal, quando inquiridos sobre a rede social a que mais recorrem ao discutirem assuntos ligados à política, 75\% dos jovens disseram conversar sobre assuntos políticos mais vezes com os amigos do que com a família. Estes dados confirmam a hipótese 
discutida por Calenda \& Meijer (2011) sobre a migração de interesses conectivos cada vez mais centrados nas relações extrafamiliares, sendo que, em grande medida, isto se dá por causa do papel do grupo de amigos e das questões de sociabilidade na juventude, atualmente bastante mediada pela internet como meio e espaço de conversação.

No contexto português, constatamos que as novas demandas criativas on-line no âmbito sociopolítico, bem como o alargamento das redes sociais dos jovens e nativos digitais constituem um novo paradigma relacional, comunicativo e interventivo, desenvolvido em rede. No entanto, esta realidade não é transversal a todos os jovens. O inquérito aplicado a três universos de grupos juvenis ligados à política permitiu identificar a relação entre o uso da internet em contextos sociopolíticos e o perfil socioeconômico destes jovens. Em termos sociográficos, a escolaridade e a faixa etária revelaram-se, na nossa análise, como indicadores do perfil dos jovens portugueses que estão utilizando a internet para socializar-se politicamente.

Os dados sobre a frequência diária dos jovens conectados à internet, principalmente em casa, e a importância dada a este meio no consumo de informações e na socialização política revelam índices da cultura cívica on-line no contexto português. Por outro lado, os recursos on-line são melhor aproveitados por quem detém literacia e tem grau educacional superior. A população de jovens entre os 15 e 20 anos que ainda frequenta a escola ou universidade, cuja grande maioria ainda não está inserida no mercado de trabalho, utiliza a internet predominantemente como forma de consumo e informação do que como instrumento de mobilização. O grupo de jovens entre 23 e 30 anos com formação superior é o que se sente mais motivado a explorar os recursos on-line, criar blogs, organizar protestos e produzir conteúdos relevantes.

Durante as eleições presidenciais, verificamos que mais de $50 \%$ dos jovens inquiridos disseram participar dos eventos divulgados nas páginas de seus grupos no Facebook, o que demonstra uma dinâmica interativa entre o on-line e o off-line neste período. Também faz-se importante sublinhar que o contexto eleitoral motiva ideologicamente os jovens, sobretudo aqueles conectados aos grupos juvenis partidários. Assim, este ponto abre caminhos para posteriores estudos fora do contexto eleitoral, o que eventualmente poderá possibilitar a comparação com o nível de engajamento on-line, fora daquele contexto.

Quanto ao grau de satisfação dos jovens portugueses no que compete à democracia, confirma-se a percepção negativa que estes têm sobre as expectativas e o rumo político do país, mantendo-se o grau de insatisfação apurado também em outros temas, ${ }^{9} \mathrm{em}$ nível nacional.

Portanto, das discussões apresentadas pontuamos o tema juventude, política e internet, chamando a atenção para o fato de que as novas ferramentas digitais podem tornar os jovens mais ativos neste campo. As novas formas de expressão política através das redes sociais on-line, blogs, vídeos e fóruns de participação são maneiras de fazer com que as propostas de muitos jovens se deem a conhecer. Do ponto de vista das políticas públicas voltadas para os jovens, pode ser este fenômeno um alerta às autoridades governamentais, no sentido servir de incentivo à participação juvenil no campo da cidadania, por meio do diálogo e para a promoção de uma sociedade incluída digitalmente.

\section{Referências}

ABÍLIO, C. Sociedade civil, democracia participativa e poder político em Portugal. Lisboa: Colibri, 2006.

ALVES, Nuno de Almeida. Perfis de utilizadores da internet em Portugal. Revista Análise Social, n 188, v. XLIII (3º, p. 603-625, 2008.

AMARAL, A. Autoetnografia e inserção on-line: o papel do "pesquisador insider" nas práticas comunicacionais das subculturas da web. Disponível em: <http://www.compos. org.br/data/biblioteca_315.pdf>. Acesso em: 19 ago. 2010.

AMARAL, I. A emergência dos weblogs enquanto novos actores sociais. In: $1^{\circ}$ ENCONTRO NACIONAL LUSOGALAICO, Universidade do Porto, 2006.

BALKIN, Jack M. Virtual Liberty: freedom to design and freedom to play in virtual worlds. Virginia Law Review, 2005.

BAYM, Nancy K. Tune in, $\log$ on: soaps, fandom, and online community. Thousand Oaks, CA: Sage Publications, 2000.

BENNETT, W. L. Civic Life On-line. Cambridge, MA: The MIT Press, 2008. 
BUCKINGHAM, D. Introducing Identity. MacArthur Foundation Series on Digital Learning - Youth, Identity, and Digital. Cambridge, MA: The MIT Press, p. 1-24, 2008.

. After the Death of Childhood: Growing Up in the Age of Electronic Media. Cambridge: Polity Press, 2000. CALENDA, D.; MEIJER, A. Political Individualization: new media as an escape from family control on political behaviour. Information, Communication \& Society, v. 14, $\mathrm{n}^{\mathrm{o}}$ 5, p.1-24, 2011.

CANAVILHAS, J. Dojornalismo on-line ao webjornalismo: formação para a mudança. Comunicação e Sociedade, v. 9-10, p. 113-119, 2006

CARDOSO, G. Os media na sociedade em rede. Lisboa: Fundação Calouste Gulbenkian, 2006.

CARDOSO G.; ESPANHA, R. E-Generation 2008: os usos de media pelas crianças e jovens em Portugal. Lisboa: CIES-ISCTE, 2008.

CARVAlHO, T.; CASANOVA, J. Esfera pública, democracia e internet: os bloggers em Portugal. Observatorio (OBS) Journal, v. 4, nº 2, p. 91-118, 2010.

CASTELLS, M. A Era da Informação: economia, sociedade e cultura. A Sociedade em Rede. 3. ed. Lisboa: Fundação Calouste Gulbenkian, 2008.

CAVANAGH. A. Sociology in the Age of the Internet. UK: Open University Press, 2007.

CALHOUN, C. (Ed.). Habermas and the public sphere. Cambridge: The MIT Press, 2008.

COLEMAN, S. How democracies have disengaged from young people. In: LOADER, Brian (Ed.) Young Citizens in the Digital Age: Political Engagement, Young People and New Media. London: Routledge, 2009. p. 166-184.

CRUZ, M. B. A participação política da juventude em Portugal: as elites políticas juvenis. Análise Social, $3^{\text {a }}$ série, v. 25, no 105-106, p. 223-249, 1989.

DELGADO, D. Estado-nación y globalización. Buenos Aires: Ariel, 2008.

DILMAN, D. A. Mail and Internet Surveys: the tailored design method. Hoboken, New Jersey: John Wiley \& Sons, 2007.

GIDDENS, A. Modernidade e identidade pessoal. Oeiras: Celta, 2007.

HAGUE. N. B,; LOADER. B. D. Digital democracy: discourse and decision making in the information age. London: Routledge, 1999.

HEANEY, F. The Short Life of Flash Mobs. Stay Free! Magazine. Disponível em: http://www.stayfreemagazine. org/archives/24/flash-mobs-history.html. Acesso em: 18 mar. 2011.

HINE, C. Virtual Ethnography. London: Sage Publications, 2000.

KEREN, M. Blogosphere: the new political arena. Lanham: Lexington Books, 2006.

JONES, Q. Virtual-Communities, Virtual Settlements \& Cyber-Archaeology: a theoretical outline. Journal of Computer - mediated Communications, v. 3, n 3, 1997.
Acessível a $1^{\circ}$ de março de 2008.

LIVINSTONE, S. The challenge of engaging youth online: contrasting producers' and teenagers' interpretations of websites. European Journal of Communication, v. 22, $\mathrm{n}^{\circ}$ 2, p. 165-184, 2006. Disponível em: http://eprints.lse. ac.uk/2769. Acesso em: 10 jan 2011.

LIVINSTONE, S.; COULDRY, N.; MARKHAM, T. Youthful steps towards civic participation: does the internet help? In: LOADER, B. (Ed.) Young Citizens in the Digital Age: political engagement, young people and new media. London: Routledge, 2007. p. 21-34.

LOADER, B (Ed). Young Citizens in the Digital Age: political engagement, young people. London: Routledge, 2007.

MALINOWSKI, B. K. Os argonautas do Pacífico Ocidental. São Paulo: Abril, 1978.

MELUCCI, A. Silencio y voz juveniles. Individualidad y compromiso en la experiencia cotidiana de los adolescentes. In: MELLUCCI, A. Vivencia y convivencia. Teoría social para una era de la información (Edición de J. Casquette). Madrid: Trotta, 2001.

MONTGOMERY, K. Youth and Digital Democracy: intersections of practice, policy, and the marketplace. In: Civic Life On-line. Cambridge, MA: The MIT Press, 2008.

MORAES, D. O ativismo digital, 2008. Disponível em: http://www.uarte.rcts.pt. Acesso em: 10 de jun. 2010.

NAYAR, P. K. Virtual Worlds: Culture and Politics in the Age of Cybertechnolog. New Delhi/Thousand Oaks, CA: Sage Publications, 2004.

NOVAES, Regina; Vital, Christina. A juventude de hoje: (re) invenções da participação social. In: THOMPSON, Andrés A. Associando-se à juventude para construir o futuro. São Paulo: Peirópolis. 2005. p. 107-148.

OBERCOM (o Observatório da Comunicação). Relatório Nativos Digitais Portugueses: idade, experiência e esferas de utilização das TICs. Disponível em: http://www.obercom. pt/content/676.np3. Acesso em: 18 jul. 2010.

O'REILLY, T. What Is Web 2.0: design patterns and business models for the next generation of software. 2005 . Disponível em: http://oreillynet.com/pub/a/oreilly/tim/ news/2005/09/30/what -is-web-20.html. Acesso em: 20 mar. 2011.

KOZINETS, R. V. Netnography: doing ethnographic research on-line. London: Sage Publications, 2010.

PALACIOS, M. Cotidiano e sociabilidade no cyberespaço: apontamentos para discussão. Disponível em: http:// facom/ufba/br/pesq/cyber/palacios/cotidiano.html. Acesso em: 19 nov. 1998.

POSTER, M. Cidadãos, media digitais e globalização. Revista de Comunicação e Linguagens -"A cultura das redes", no extra , p. 21-34, 2000.

PAPACHARISSI, Z. The virtual sphere: the internet as a public sphere. New Media \& Society, v. 4, n 1, p. 9-27, 2007. RECUERO, R. Redes sociais na Internet: considerações iniciais, 2006. Disponível em: http://www.bocc.ubbi.pt. 
Acesso em: 18 mar. 2011.

RODRIGUES, A. D. A partitura invisivel: para uma abordagem interactiva da linguagem. Lisboa: Colibri, 2001.

Comunidades virtuais: uma abordagem teórica, 2006. Disponível em: www.bocc.ubbi.pt. Acesso em: 18 mar. 2011.

. Redes sociais na Internet. Porto Alegre: Sulina, 2009.
TREMAYNE, M. (Ed.) Blogging, Citizenship, and the Future of Media. Nova York: Routledge, 2007.

VROMEN, A. Australian young people's participatory practices and internet use. In: LOADER, Brian (Ed.) Young Citizens in the Digital Age: Political Engagement, Young People and New Media. London: Routledge, 2007. p. 97-113.

\title{
Youth and on-line civic mobilization: presidential elections in Portugal
}

\section{(2011)}

\begin{abstract}
The internet has offered young people a space for mobilization and socialization. Links structured on social networks such as Facebook have broadened to many Portuguese young people, in some way, involved in politics, via political parties or associations. This paper is the result of an on-line survey conducted during 2011 presidential election in Portugal. Young people affiliated to party associations (JSD and JP) and to a non-partisan one (MLS) took part of it. The goal was to observe the impacts internet can have on young peoples' civic lives, how these resources are explored and if they effectively promote youth participation in relevant public issues.
\end{abstract}

Key words: young people and politics, social networks, on-line civic culture, partisan youths, civic mobilization.

\section{Juventud partidista y movilización ciudadana en línea: el caso de las elecciones presidenciales en Portugal (2011)}

\section{Resumen}

El ciberespacio ha demostrado un medio propicio a la movilización y la socialización de los más jóvenes permitindo a ellos convocar sus propuestas de articulación en común. Para muchos jóvenes portugueses conectados de alguna manera en la politica através de los partidos políticos o asociaciones, estructurados en redes sociales de amigos (y amigos de amigos) amplián más y están mediadas en el contexto de las redes sociales como Facebook. Este trabajo es el resultado de una encuesta en línea aplicada en relación con la elecciones presidenciales de 2011 en Portugal. Fueran encuestados jóvenes de las asociaciones partidistas (JSD - JP) y no partidista (MLS) con el fin de verificar el impacto que los medios digitales, incluyendo la Internet puede jugar en la vida cívica de los jóvenes, también si estos recursos son explotados y eficaz, si estos medios de comunicación colaboran en el fomento de la participación juvenil en asuntos de importancia pública.

Palabras-clave: jovenes y politica, red sociales, cultura cívica on-line, partidos de los jóvenes, movilización cívica. 